\title{
A model of formulation of blended binders for use in cemented mine backfills
}

\author{
T. Belem Université du Québec en Abitibi-Temiscamingue, Canada \\ O. Peyronnard Université du Québec en Abitibi-Temiscamingue, Canada
}

M. Benzaazoua Université du Québec en Abitibi-Temiscamingue, Canada

\begin{abstract}
In this paper, a model has been proposed for determining the relative chemical reactivity of blended binders for use cemented mine backfills. This model can be used for rational formulation of blended binder by using a concept of 'corresponding reactivity' based on a reference blended binder. The implementation of the proposed model will help reducing the number of batch to be prepared during the optimisation of mix recipes.
\end{abstract}

\section{$1 \quad$ Introduction}

Cemented mine backfill (CMB) is an integral part of modern mining methods which combine good productivity and effective integrated management of solid waste. The disposal of mine waste underground reduces the environmental impact and provides a material that improves both ground support and the economics of mining. Indeed, the purpose of the CMB is to increase the load bearing capacity of the wall rock and to improve load shedding to crown pillars. The self-supporting of CMB allows increased ore reserves extraction. CMB is a mixture of solid waste (e.g. waste rock, deslimed mill tailings, total filtered mill tailings, crushed rock, other), hydraulic binder and mixing water. The purpose of hydraulic binder addition is to generate typical unconfined compressive strengths (UCS) ranging from $500 \mathrm{kPa}$ to $>10 \mathrm{MPa}$, depending on the type of backfill. CMB cost generally accounts for between $10 \%$ and $20 \%$ of the total operating cost of the mine and hydraulic binder represents up to $80 \%$ of that cost (Grice, 1998). One of the promising options to reduce backfilling operation costs is partial replacement of typical hydraulic cement by industrial by-products and other supplementary cementitious materials (SCM). Indeed, the smallest gain in binder proportion can result in appreciable money saving (Belem and Benzaazoua, 2007). The main objective of this study is to propose a model of formulation of blended binders for use in CMB mixtures.

\section{Background on cementitious materials}

Cementitious material is defined by American Concrete Institute (ACI) as an inorganic binding medium that combines with aggregate and water to form concrete. Hydraulic material has the ability to react with water to form a solid. Cement is a hydraulic powder, which reacts with water to form a solid mass. Among the many types of hydraulic cement, the most common in use is Portland cement (PC). Materials broadly considered 'cementitious' include Portland cements, fly ash, ground granulated blast-furnace slag (GBFS), natural pozzolans, silica fume, and blended hydraulic cements. Blended hydraulic cements (mixtures of PC with other reactive material) are also known as composite cement. The reactive materials used in blended cements can be natural or industrial by-products, also designated as supplementary cementitious materials.

\subsection{Types of PC}

Different types of PC are manufactured to meet various physical and chemical requirements. The Canadian Standard Association (CSA) and the American Society for Testing and Materials (ASTM) provide for six types of PC. Standards A5-98 and C150 are materials-specific and provide for 6 types of PC, whereas standards A3001-03 and C1157 are performance-oriented and provide for 7 types of PC. These designations are: I or GU (general use Portland cement), II or MS/MH (moderate sulfate-resistant cement/moderate heat of hydration hydraulic cement), III or HE (high early-strength cement), IV or LH (low heat of hydration 
cement) and V or HS (high sulfate-resistant cement). Portland cement is a finely ground gray powder chemically formed by combining and heating raw materials containing calcium oxide $(\mathrm{CaO})$, silica $\left(\mathrm{SiO}_{2}\right)$, alumina $\left(\mathrm{Al}_{2} \mathrm{O}_{3}\right)$, and iron oxide $\left(\mathrm{Fe}_{2} \mathrm{O}_{3}\right)$ to obtain the clinker. This clinker is inter-ground with a small amount (typically 3 to 7\%) of gypsum (calcium sulfate dihydrate) and/or anhydrite (calcium sulfate) in order to control setting behaviour, strength development, and volume stability. The major oxides in clinker are combined essentially into four clinker minerals, denoted in shorthand: tricalcium silicate $\left(\mathrm{C}_{3} \mathrm{~S}\right)$ or 'alite', dicalcium silicate $\left(\mathrm{C}_{2} \mathrm{~S}\right)$ or 'belite', tricalcium aluminate $\left(\mathrm{C}_{3} \mathrm{~A}\right)$, and tetracalcium aluminoferrite $\left(\mathrm{C}_{4} \mathrm{AF}\right)$. Oxides are referred to by their first letter, for all the oxides likely to be encountered in cementitious systems, as follows: $\mathrm{C}=\mathrm{CaO}, \mathrm{M}=\mathrm{MgO}, \mathrm{S}=\mathrm{SiO}_{2}, \mathrm{~A}=\mathrm{Al}_{2} \mathrm{O}_{3}, \mathrm{~F}=\mathrm{Fe}_{2} \mathrm{O}_{3}, \mathrm{~K}=\mathrm{K}_{2} \mathrm{O}, \mathrm{N}=\mathrm{Na}_{2} \mathrm{O}, \mathrm{T}=\mathrm{TiO}_{2}, \mathrm{H}=\mathrm{H}_{2} \mathrm{O}, \overline{\mathrm{S}}=\mathrm{SO}_{3}$ and $\overline{\mathrm{C}}=\mathrm{CO}_{2}$. These formulas represent averages, ignoring impurities commonly found in actual clinker.

In the presence of water, the cement compounds chemically combined with water (hydrate) to form new compounds that are the infrastructure of the hardened cement paste in concrete. Both $\mathrm{C}_{3} \mathrm{~S}$ and $\mathrm{C}_{2} \mathrm{~S}$ hydrate to form calcium hydroxide or portlandite $(\mathrm{CH})$ and calcium silicate hydrate $(\mathrm{C}-\mathrm{S}-\mathrm{H})$. Hydrated cement paste contains 15 to $25 \%$ calcium hydroxide and about $50 \%$ C-S-H by mass. The strength and other properties of hydrated cement are due primarily to $\mathrm{C}-\mathrm{S}-\mathrm{H} . \mathrm{C}_{3} \mathrm{~A}$ reacts with water and calcium hydroxide to form tetracalcium aluminate hydrate. $\mathrm{C}_{4} \mathrm{AF}$ reacts with water and calcium hydroxide to form calcium aluminoferrite hydrate. In concrete (or mortar or other cementitious materials) there are typically four main types of cementitious hydrated minerals: C-S-H, CH, AFm (e.g. monosulfate) and AFt (e.g. ettringite) phases. The $\mathrm{Si} / \mathrm{Ca}$ ratio is somewhat variable but typically approximately $0.45-0.50$ (Mindess and Young, 1981).

\subsection{Supplementary cementitious material}

Supplementary cementitious materials contribute to the properties of hardened materials through hydraulic or pozzolanic reaction (natural pozzolans, fly ash, blast furnace slag, silica fume).

Fly ash (FA): Is comprised of the non-combustible mineral portion of coal consumed in a coal fueled power plant. Fly ash particles are glassy, spherical shaped 'ball bearings' that are collected from the combustion airstream exiting the power plant. FA is classified as either Class $\mathrm{F}$ or Class $\mathrm{C}$ reflecting a difference in chemical composition and origin. Class $\mathrm{F}$ fly ashes $(\mathrm{FaF})$ possess largely pozzolanic properties. Class $\mathrm{C}$ fly ashes $(\mathrm{FaC})$ generally possess hydraulic as well as pozzolanic properties. ASTM C618 differentiates Class C and Class $\mathrm{F}$ fly ashes based on the sums of $\mathrm{S}+\mathrm{A}+\mathrm{F}$. For Class $\mathrm{C}$ fly ash, the sum $(\mathrm{S}+\mathrm{A}+\mathrm{F}) \geq 50 \%$. For Class F fly ash, the sum of $(\mathrm{S}+\mathrm{A}+\mathrm{F}) \geq 70 \%$. The Class $\mathrm{C}$ fly ashes essentially contain 15 to $25 \%$ calcium, which makes their performance characteristics different from a low-calcium Class F fly ash (ACI).

Ground granulated blast furnace slag (GBFS): In the production of iron, a blast furnace typically is charged with iron ore, flux stone (limestone or dolomite), and petroleum coke for fuel. The two products obtained from the furnace are molten iron and slag. Consisting primarily of silica and alumina from the iron ore combined with calcium from the flux stone, slag contains the same major elements as PC but in different proportions (see Table 1). Ground granulated blast furnace slag (GBFS) used as a cementitious material, however, is comprised essentially of glasses (latent hydraulic properties).

Silica fume $(S F)$ : is a by-product of the silicon and ferrosilicon metal manufacturing process. This finely divided, glassy powder results from the condensation of silicon oxide gas. Silica fume is composed primarily of silicon dioxide $\left(\mathrm{SiO}_{2}\right)$. Particles are about 100 times smaller than the typical particles of PC. Silica fume is a very reactive pozzolanic material due to a higher surface to volume ratio. Silica fume is used to increase strength and durability of concrete, but generally requires the use of superplasticisers for workability (ACI).

\subsection{Blended hydraulic cements}

Blended cements are intimate mixes of a PC base (generally Type I or GU) with one or more SCM extenders. The SCM commonly makes up about 5 to $80 \%$. In blended cements, the SCM (or pozzolans) are activated by the high $\mathrm{pH}$ resulting from the hydroxide ions released during the hydration of PC (Mindess and Young, 1981). 


\subsubsection{Specifications by standards}

Blended hydraulic cements conform to the requirements of ASTM C595 or C1157. There are five classes of blended cement in C595: Portland blast furnace slag cement (IS: 25 to 70\% GBFS), Portland-pozzolan cement (IP and P: 15 to $40 \%$ pozzolans), Pozzolan-modified portland cement (I(PM): less than 15\% pozzolan), Slag-modified portland cement (I(SM): less than 25\% GBFS), and Slag cement (S: $\geq 70 \%$ GBFS). Although blended cements are common in European countries, they have not been used as extensively in North America, but are gaining popularity because they require less energy to manufacture, they can be made with by-product materials that would normally be disposed in landfills, thus reducing solid waste, and offer performance benefits for certain applications (ACI). Blended cements meeting the requirements of ASTM C1157 or CSA A3001-03 meet physical performance test requirements without prescriptive restrictions on ingredients or cement chemistry.

\subsubsection{Advantage of blends}

Figure 1 is an illustration of why blends perform better. Figure 1a shows that when general use PC Type I or GU hydrates, C-S-H gel is formed (glue) which holds aggregates together. However, gaps in this glue provide pathways for moisture to penetrate and reduce strength. Figure $1 \mathrm{~b}$ shows that when SCM is added, hydration products pack more tightly within the voids and additional glue forms from the SMC hydration process. With fewer voids, the material is less permeable and stronger. Blends can be divided into two main categories: binary and ternary. Binary is a mixture with two products, i.e. PC and one SCM, whereas the ternary blend is a mixture of three products, i.e. PC and two SCM. While very rare, quaternary blends (i.e. PC and three SCM) do exist, and typically comprise PC, silica fume, slag and fly ash (Lafarge North America).

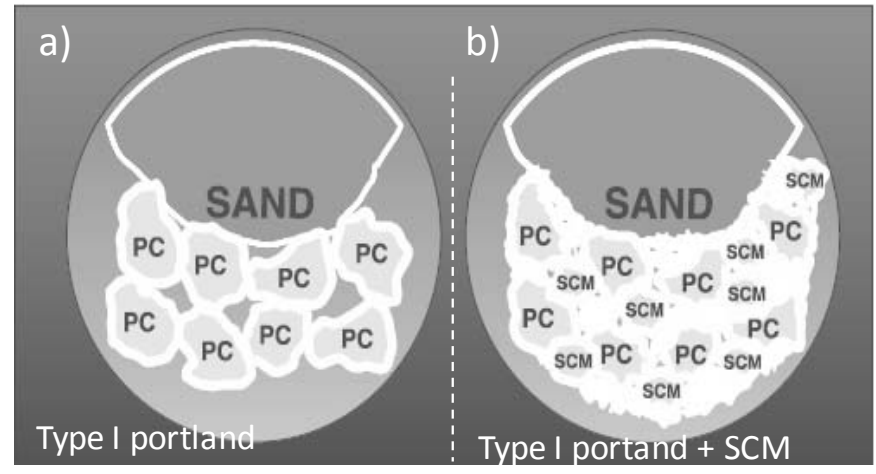

Figure 1 Schematic diagram showing the difference in concrete microstructure: a) Type I PC hydrates (C-S-H glue with gaps); b) Type I + SCM hydrates (more C-S-H glue packed tightly) (adapted from Lafrage North America)

\subsection{Chemical and physical properties of cementitious materials}

Portland cement, slag, and fly ash share chemical similarities. They all contain similar oxides, though the proportions are different (Table 1). Physical properties of cementitious materials include fineness $\left(S_{\mathrm{m}}\right) /$ grain size distribution, setting time, compressive strength (UCS), heat of hydration, specific gravity $\left(\mathrm{G}_{\mathrm{s}}\right)$, and loss of ignition (L.O.I.). The fineness of cement affects the amount of heat released during hydration. Greater cement fineness (smaller particle size) increases the rate at which cement hydrates and thus accelerates strength development. The effects of greater fineness on strength are generally seen during the first seven days (ACI). Table 2 presents the physical properties of PC and SCM.

\subsection{Mining applications}

The mining industry is a large user of cement, concrete, and SCM. For instance, silica fume in dry-bag is commonly used for shotcreting applications in mine tunnels and shafts. It is the mine backfill, however, that uses large amounts of SCM. About 50,000 and 120,000 t of fly ash and slag, respectively, are consumed every year in mining applications in Quebec and Ontario. 
Table 1 Chemical composition of Portland cement and SCM (mean values)

\begin{tabular}{llllllll}
\hline Type of Cement & $\begin{array}{l}\mathbf{S i O}_{2} \\
(\mathbf{w t} \%)\end{array}$ & $\begin{array}{l}\mathbf{A l}_{2} \mathbf{O}_{3} \\
(\mathbf{w t} \%)\end{array}$ & $\begin{array}{l}\mathbf{F e}_{2} \mathbf{O}_{3} \\
(\mathbf{w t \%})\end{array}$ & $\begin{array}{l}\mathbf{C a O} \\
(\mathbf{w t} \%)\end{array}$ & $\begin{array}{l}\mathbf{M g O} \\
(\mathbf{w t} \%)\end{array}$ & $\begin{array}{l}\mathbf{S O}_{3} \\
(\mathbf{w t} \%)\end{array}$ & $\begin{array}{l}\text { Alkali } \\
(\mathbf{w t} \%)\end{array}$ \\
\hline Type I (GU) & 20.5 & 5.4 & 2.6 & 63.9 & 2.1 & $1-4.5$ & $0.2-1.3$ \\
Type II (MH \& MS) & 21.2 & 4.6 & 3.5 & 63.8 & 2.1 & $1-4.5$ & $0.2-1.3$ \\
Type III (HE) & 20.6 & 4.9 & 2.8 & 63.4 & 2.2 & $1-4.5$ & $0.2-1.3$ \\
Type IV (LH) & 22.2 & 4.6 & 5 & 62.5 & 1.9 & $1-4.5$ & $0.2-1.3$ \\
Type V (HS) & 21.9 & 3.9 & 4.2 & 63.8 & 2.2 & $1-4.5$ & $0.2-1.3$ \\
Class F fly ash (FaF) & 52 & 23 & 11 & 5 & 2 & 0.8 & 2.3 \\
Class C fly ash (FaC) & 35 & 18 & 6 & 21 & 5 & 4.1 & 6.3 \\
Blast furnace slag (GGBS) & 36 & 10 & 0.5 & 39 & 12 & $0.6-2$ & 0.6 \\
Silica fume (SF) & 90 & 0.4 & 0.4 & 1.6 & 1.7 & 0.4 & 2 \\
\hline
\end{tabular}

Table 2 Physical properties of Portland cement and SCM (different sources)

\begin{tabular}{llllllllll}
\hline & $\begin{array}{l}\text { Type } \\
\text { I }\end{array}$ & $\begin{array}{l}\text { Type } \\
\text { II }\end{array}$ & $\begin{array}{l}\text { Type } \\
\text { III } \\
\text { (GU) }\end{array}$ & $\begin{array}{l}\text { Type } \\
\text { IV } \\
\text { (HE) }\end{array}$ & $\begin{array}{l}\text { Type } \\
\text { V }\end{array}$ & $\begin{array}{l}\text { Class } \\
\text { C fly }\end{array}$ & $\begin{array}{l}\text { Class } \\
\text { F fly } \\
\text { ash }\end{array}$ & $\begin{array}{l}\text { Slag } \\
\text { (GGBS) }\end{array}$ & $\begin{array}{l}\text { Silica } \\
\text { fume, } \\
\text { FS }\end{array}$ \\
\hline $\begin{array}{l}\text { Blaine } S_{\mathrm{m}} \\
\left(\mathrm{cm}^{2} / \mathrm{g}\right)\end{array}$ & 3,690 & 3,770 & 5,480 & 3,400 & 3,730 & 4,200 & 4,200 & 5,000 & 200,000 \\
$\rho_{\mathrm{s}}(\mathrm{g} / \mathrm{cm} 3)$ & 3.15 & 3.18 & 3.15 & 3.15 & 3.19 & 2.38 & 2.58 & 2.94 & 2.35 \\
$d_{\mathrm{av}}(\mathrm{cm})$ & 0.0015 & 0.0014 & 0.001 & 0.002 & 0.0015 & 0.0025 & 0.001 & 0.0011 & 0.000015 \\
\hline
\end{tabular}

SCM are also used in mines in western Canada, but the amount has not been determined (Bouzoubaâ and Fournier, 2005). In the mining industry, cementitious materials are termed 'binders' mainly due to the higher water-to-cementitious ratio $(w / \mathrm{cm}>3)$ used. Type I (or $\mathrm{GU})$ portland cement is the most popular binder used worldwide in cemented mine backfilling operations alone or blended with SCM (fly ashes and GGBS). When tailings are very reactive (presence of pyrite and pyrrhotite) and/or contain higher levels of sulfate, Type V (or HS) portland cement is used for backfill preparation. However, Type V cement has mainly been supplanted by the use of Type I (GU) cement blended with GGBS or ternary blended cements containing GGBS and fly ash (Benzaazoua et al., 2010). Based on the works done by Benzaazoua et al. (2004a), it must be recognised that the hardening processes in CMB are very different to those encountered in mortar and concrete. No direct transposition or extrapolation can be made between concrete/mortar and CMB in view of understanding their behaviour (Benzaazoua et al., 2004a, 2010). For more details concerning the key issues related to the use of binders in CMB, see Benzaazoua et al. (2010).

\section{Model development}

For now, the use of cement and SCM in cemented mine backfills is not regulated by any standard. Thus, the choice of the adequate binder to use with a given type of mine tailings is based mainly on the experience of a skilled person and laboratory tests based on factorial mix design. The purpose of developing a model is to have a tool for preliminary assessment of the basic chemical compositions of potential optimal blended binders for use with a given type of tailings in CMB mixture. 


\subsection{Basic considerations}

\subsubsection{Blended binders}

A blended binder $(B b)$ is defined as a blend of a basic portland cement $(P C)$, which is mostly the general use cement GU (or Type I) and its replacement $\left(P C_{\text {rep }}\right)$. The PC replacement can be one of the other portland cements (such as moderate sulfate resistant cement MS or Type II, high sulfate resistant cement HS or Type V) and/or supplementary cementitious materials SCM. Each cement or SCM is termed binder $(B)$. If PC is used alone (Types GU, MS or HS) it will be a primary binder $B$. The blended binder $B b$ will be binary, ternary or quaternary if one PC is blended with one, two or three binders. However, only primary $(B)$ and binary $(B b)$ binders are most common in mining industry. The four major oxides can describe either a binder $B$ or a blended binder $B b$ chemical composition as follows:

$$
[B],[B b]=[\% S ; \% A ; \% F ; \% C]_{w t \%}
$$

Where:

$$
\begin{array}{lll}
\% \mathrm{~S}=\% \mathrm{SiO}_{2} & = & \text { percentage of silica }(\mathrm{wt} \%) . \\
\% \mathrm{~A}=\% \mathrm{Al}_{2} \mathrm{O}_{3} & = & \text { percentage of alumina }(\mathrm{wt} \%) . \\
\% \mathrm{~F}=\% \mathrm{Fe}_{2} \mathrm{O}_{3} & = & \text { percentage of iron oxide or ferrite }(\mathrm{wt} \%) . \\
\% \mathrm{C}=\% \mathrm{CaO} & = & \text { percentage of calcium oxide or lime }(\mathrm{wt} \%) .
\end{array}
$$

By definition, a blended binder $B b$ is expressed by the following relationship:

$$
B b=y P C+\sum_{i=1}^{n} x_{i}\left(P C_{r e p}\right)_{i} \text { and } y+\sum_{i=1}^{n} x_{i}=1
$$

and, in terms of chemical composition as follows:

$$
[B b]=y[P C]+\sum_{i=1}^{n} x_{i}\left[B_{i}\right]
$$

Where:

$y=$ fractional proportion of the basic $P C$ used (= Types GU or I).

$x=\quad$ fractional proportion of portland cement replacement.

$i=1,2,3, \ldots n=$ number of binders in the blend $(1=$ binary, $2=$ ternary, $3=$ quaternary $)$.

$B_{\mathrm{i}} \quad=\quad i$ th binder type in the blend (e.g. $B_{1}=$ class F fly ash, $B_{2}=$ GGBS).

For a binary blended binder, $i=n=1$ and $B b=y P C+(1-\mathrm{y}) P C_{\text {rep. }}$. For example, if $P C=\mathrm{GU}$ and $P C_{\text {rep }}=$ class $\mathrm{C}$ fly ash $(\mathrm{FaC})$ then $B b=y \mathrm{GU}+(1-\mathrm{y}) \mathrm{FaC}$.

\subsubsection{Hydraulic modulus}

The hydraulic activity of a single binder can be defined in different manners based on the amount of the main major oxides (S, A, F, C and MgO). Many authors quantify the hydraulic activity of pozzolans and GGBS based on chemical indexes called hydraulic moduli. These moduli are defined in terms of basicity and quality. The higher a hydraulic modulus is, the higher the binder reactivity or hydraulic activity. However, it was found that the correlation between these moduli and the strength of blended cements is not always good (e.g. Wang et al., 1994; Pal et al., 2003). According to Kamon and Nontananandh (1991), two considerations are important in the formulation of a blended binder: i) the total amount of oxide, and ii) the self-cementing characteristics. Kamon and Nontananandh (1991) stated that the self-cementing characteristic is expressed in terms of a hydraulic modulus, which is defined as follows:

$$
\frac{\% \mathrm{CaO}}{\% \mathrm{SiO}_{2}+\% \mathrm{Al}_{2} \mathrm{O}_{3}+\% \mathrm{Fe}_{2} \mathrm{O}_{3}}=\frac{\% \mathrm{C}}{\% \mathrm{~S}+\% \mathrm{~A}+\% \mathrm{~F}}
$$


The hydraulic modulus is determined with reference to those of 'alite' $\left(\mathrm{C}_{3} \mathrm{~S}\right)$ and 'belite' $\left(\mathrm{C}_{2} \mathrm{~S}\right)$ cement compounds, since these two phases are largely responsible for initial set and early strength (alite) and for strength increases beyond one week (belite). As a target for binder control, the hydration modulus should be within the range of 1.7, approximately corresponding to belite, and 2.4, approximately corresponding to alite. For this reason, $\mathrm{CaO}$ can be added in the form of lime (Kamon and Nontananandh, 1991). From Equation (3) the hydraulic modulus for a blended binder $B d$ can be expressed as follows:

$$
H m_{B b}=\frac{\sum_{i=0}^{n} y_{i}(\% \mathrm{CaO})_{i}}{\sum_{i=0}^{n} y_{i}\left(\% \mathrm{SiO}_{2}\right)_{i}+\sum_{i=0}^{n} y_{i}\left(\% \mathrm{Al}_{2} \mathrm{O}_{3}\right)_{i}+\sum_{i=0}^{n} y_{i}\left(\% \mathrm{Fe}_{2} \mathrm{O}_{3}\right)_{i}}
$$

and the corresponding contribution for single binder $h m_{\mathrm{b}}$ in the total hydraulic modulus $H m_{\mathrm{Bb}}$ of a blended binder $B b$ is given as follows:

$$
\left(h m_{b}\right)_{i}=\frac{y_{i}(\% \mathrm{CaO})_{i}}{\sum_{i=0}^{n} y_{i}\left(\% \mathrm{SiO}_{2}\right)_{i}+\sum_{i=0}^{n} y_{i}\left(\% \mathrm{Al}_{2} \mathrm{O}_{3}\right)_{i}+\sum_{i=0}^{n} y_{i}\left(\% \mathrm{Fe}_{2} \mathrm{O}_{3}\right)_{i}}
$$

Where:

$y_{\mathrm{i}}=$ fractional proportion of the $i$ th binder in the blend; $i=0$ corresponds to the basic portland cement (= Type GU or I).

Let $\sum_{i=0}^{n} y_{i}(\% C a O)_{i}=\% C_{B b} ; \sum_{i=0}^{n} y_{i}\left(\% S i O_{2}\right)_{i}=\% S_{B b} ; \sum_{i=0}^{n} y_{i}\left(\% A l_{2} O_{3}\right)_{i}=\% A_{B b} ; \sum_{i=0}^{n} y_{i}\left(\% F e_{2} O_{3}\right)_{i}=\% F_{B b}, \quad$ and $y_{i}(\% \mathrm{CaO})_{i}=\left(\% C_{B}\right)_{i}$. Equation (4) can be rewritten as follows:

$$
H m_{B b}=\frac{\% C_{B b}}{\% S_{B b}+\% A_{B b}+\% F_{B b}}
$$

and

$$
\left(h m_{b}\right)_{i}=\left(\% C_{B}\right)_{i} \cdot\left(\% S_{B b}+\% A_{B b}+\% F_{B b}\right)^{-1}
$$

thus

$$
H m_{B b}=\left(\% S_{B b}+\% A_{B b}+\% F_{B b}\right)^{-1} \cdot \sum_{i=0}^{n}\left(\% C_{B}\right)_{i}=\sum_{i=0}^{n}\left(h m_{b}\right)_{i}=\left(h m_{b}\right)_{G U}+\sum_{i=1}^{n}\left(h m_{b}\right)_{i}
$$

Using the data in Table 1, the calculated $H m_{\mathrm{B}}=2.19$ (mean) for portland cement, 0.06 for class $\mathrm{F}$ fly ash $(\mathrm{FaF}), 0.36$ for class $\mathrm{C}$ fly ash $(\mathrm{FaC}), 0.04$ for natural pozzolans $(\mathrm{N})$, and 0.91 for GBFS.

Example 1: if we consider a binary blended binder of $30 \% \mathrm{GU}$ and $70 \% \mathrm{GBFS}$, then $H m_{\mathrm{Bb}}=1.19,\left(h m_{\mathrm{b}}\right)_{\mathrm{GU}}=$ 0.48 and $\left(h m_{\mathrm{b}}\right)_{\mathrm{GGBS}}=0.71$. Example 2: if we now consider a ternary blended binder of $50 \% \mathrm{GU}, 15 \% \mathrm{GBFS}$ and 35\% Class C fly ash $(\mathrm{FaC})$, then $H m_{\mathrm{Bb}}=1.08,\left(h m_{\mathrm{b}}\right)_{\mathrm{GU}}=0.76,\left(h m_{\mathrm{b}}\right)_{\mathrm{GBFS}}=0.14$, and $\left(h m_{\mathrm{b}}\right)_{\mathrm{FaC}}=0.18$.

Figure 2 shows the evolution curves of $H m_{\mathrm{Bb}}$ as a function of Type I replacement in the blends. This figure clearly shows that the higher the $H m_{\mathrm{Bb}}$ value and the higher the hydraulic activity (self-cementing ability) of the blended binder. From Figure 2, three classes of blended binder hydraulic activity can be defined: Class I $\left(1.70 \leq H m_{\mathrm{Bb}} \leq 2.24\right)$, Class II $\left(0.36 \leq H m_{\mathrm{Bb}}<1.70\right)$ and Class III $\left(0.0 \leq H m_{\mathrm{Bb}}<0.36\right)$. The lower and upper limits in Class I blended binders correspond to those of $\mathrm{C}_{2} \mathrm{~S}$ and $\mathrm{GU}$ cement, respectively. The lower limit in Class II blended binders corresponds to that of Class $\mathrm{C}$ fly ash as it possesses hydraulic property, whereas the lower limit in Class III blended binders corresponds to non-hydraulic materials. Class I blended binders are considered as self-cementing materials, which will develop a reasonable strength at early age. This class contains all portland cements and their blends. Class II binders are considered as slow cementing materials which will develop a very good long-term strength (age $\geq 91$ days). Class III binders are supposed to have low or zero hydraulic activity and will not develop acceptable strength at either short term or long term. 


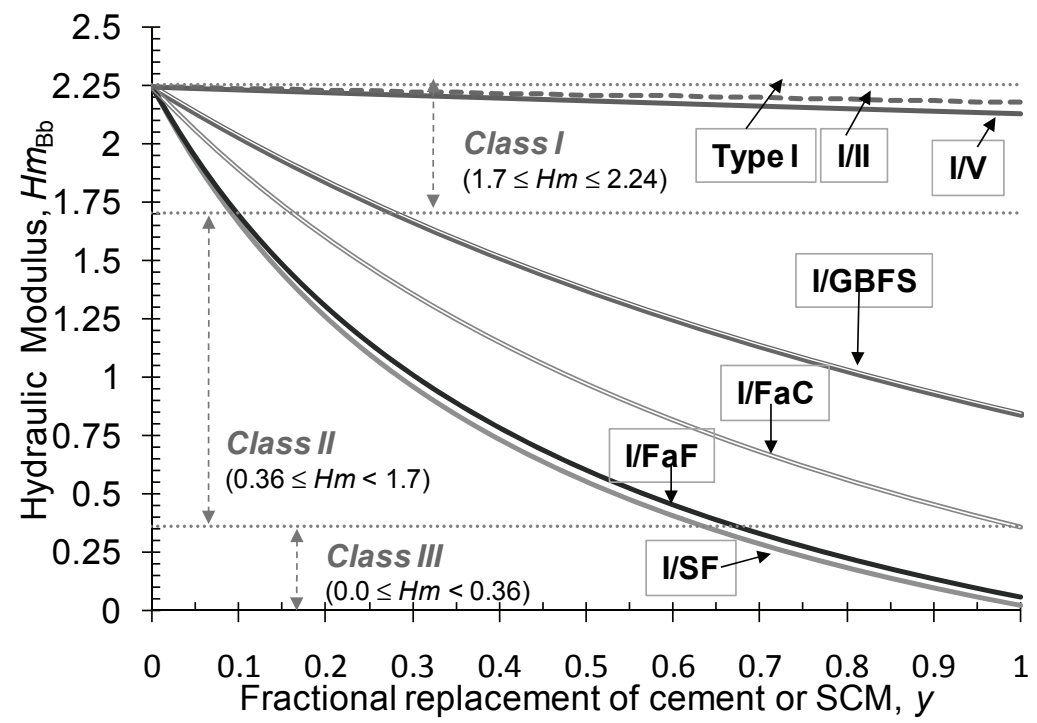

Figure 2 Evolution of hydraulic modulus $\mathrm{Hm}_{\mathrm{Bb}}$ as a function of Type I replacement $y$

\subsection{Formulation of the model}

According to ACI (1998), the factors determining cementitious properties of a binder are: the chemical composition, the mineralogical composition, alkali concentration of the reacting system, fineness (particle size), and temperature during the early phases of the hydration.

\subsubsection{Reactivity factor}

In general, increased fineness results in better strength development, particularly at early ages. The fineness is quantified by the specific surface area $S_{\mathrm{m}}$, which is the ratio of surface area $A$ and the mass $m$ of a sample $\left(S_{\mathrm{m}}=A / m\right)$. The specific surface area can be determined by BET gas adsorption $\left(S_{\mathrm{m}-\mathrm{BET}}\right)$, Blaine air permeability $\left(S_{\mathrm{mB}}\right)$ or from particle size distribution $\left(S_{\mathrm{m}-\mathrm{psd}}\right)$. There is a well-known relationship between particle fineness and its diameter $d$. Assuming spherical particles, the specific surface area $S_{\mathrm{m}}\left(\mathrm{cm}^{2}\right)$ is related to particle diameter $d(\mathrm{~cm})$ and relative density $\rho_{\mathrm{s}}\left(\mathrm{g} / \mathrm{cm}^{3}\right)$ by the following relation: $S_{\mathrm{m}}=6\left(\rho_{\mathrm{s}} d\right)^{-1}$, hence $S_{\mathrm{m}} \rho_{\mathrm{s}} d=6$. From this relation, it is clear that specific surface area $S_{\mathrm{m}}$ is inversely proportional to the particle diameter $d\left(S_{\mathrm{m}} \propto d^{-1}\right)$. Drawing on this relation, we define the reactivity factor $R_{f}$ of a binder $B$ as follows:

$$
R_{f}(B)=S_{m-b} \cdot \rho_{s-b} \cdot d_{a v-b}
$$

Where:

$S_{\mathrm{m}-\mathrm{b}}=\quad$ Blaine specific surface area of binder $\left(\mathrm{cm}^{2} / \mathrm{g}\right)$.

$\rho_{\mathrm{s}-\mathrm{b}}=\quad$ relative density of binder particles $\left(\mathrm{g} / \mathrm{cm}^{3}\right)$.

$d_{\text {av-b }}=$ average diameter of binder particles $(\mathrm{cm})$.

For spherical particles of a binder, $R_{f}(B)=6$. For a blended binder, a composite reactivity factor can be obtained from composite $S_{\mathrm{m}-\mathrm{b}}, \rho_{\mathrm{s}-\mathrm{b}}$ and $d_{\mathrm{av}-\mathrm{b}}$ as follows:

$$
\begin{gathered}
S_{m}(B b)=\left[\sum_{i=0}^{n} \frac{y_{i}}{\left(S_{m-b}\right)_{i}}\right]^{-1}=\left(\frac{y_{0}}{\left(S_{m-b}\right)_{0}}+\frac{y_{1}}{\left(S_{m-b}\right)_{1}}+\frac{y_{2}}{\left(S_{m-b}\right)_{2}}+\ldots\right)^{-1} \\
\rho_{s-b}(B b)=\left[\sum_{i=0}^{n} \frac{y_{i}}{\left(\rho_{s-b}\right)_{i}}\right]^{-1}=\left(\frac{y_{0}}{\left(\rho_{s-b}\right)_{0}}+\frac{y_{1}}{\left(\rho_{s-b}\right)_{1}}+\frac{y_{2}}{\left(\rho_{s-b}\right)_{2}}+\ldots\right)^{-1} \\
d_{a v-b}(B b)=\sum_{i=0}^{n} y_{i}\left(d_{a v-b}\right)_{i}=y_{0}\left(d_{a v-b}\right)_{0}+y_{1}\left(d_{a v-b}\right)_{1}+y_{2}\left(d_{a v-b}\right)_{2}+\ldots
\end{gathered}
$$


Where:

$y_{\mathrm{i}}=\quad$ fractional proportion of the $i$ th binder in the blend; $i=0$ corresponds to the basic portland cement (= Type GU, 10 or I).

Finally, the reactivity factor for a blended binder $B b$ is obtained as follows:

$$
R_{f}(B b)=S_{m-b}(B b) \cdot \rho_{s-b}(B b) \cdot d_{a v-b}(B b)
$$

\subsubsection{Hydraulic Activity Index}

In order to quantify the hydraulic activity of a blended binder, the hydraulic modulus $\mathrm{Hm}$ (Equations (3), (4a), (5a) or (5c)) must be weighted by the reactivity factor as the fineness of the binder plays an important role during hardening. The Hydraulic Activity Index $H_{a}$ of a binder $B$ or a blended binder $B b$ is defined with regard to the hydraulic activity of GU cement as follows:

$$
H_{a}(B, B b)=\left(\frac{H m_{B, B b}}{H m_{G U}}\right)^{2}\left(\frac{R_{f}(G U)}{R_{f}(B, B b)}\right)^{0.5} \quad 0 \leq H_{a} \leq 1
$$

Where:

$H m_{\mathrm{B}, \mathrm{Bb}}=$ hydraulic modulus of a binder $B$ or blended binder $B b$ (Equations (3), (5a) or (5c)).

$R_{f}(B, B b)=$ reactivity factor of a binder $B$, blended binder $B b$ or GU cement (Equations (6), (7), (8)).

When $H_{a}=0$ the binder/blended binder has no self-cementing property and will never react with water to form a solid mass. When $H_{a}=1$, the binder/blended binder has identical self-cementing property then general use portland cement GU (or Type I). Parameter $H_{a}$, which can also be expressed in percent $(\times 100)$ of the hydraulic activity of GU cement, can be used for discriminating hydraulic activity of different blended binders. However, it is important to note that higher self-cementing ability does not mean higher resultant strength performance, but early age strength development.

\subsubsection{Definition of reference blended binder}

The compressive strength of $\mathrm{CMB}$ is governed by physical-chemical properties and mineralogy of mine tailings along with physico-chemical properties of mixing water and the types of binder or blended binder used. Certain tailings and their waters (pore and mixing) are non-reactive, while some others and their waters are moderately to highly reactive. As demonstrated in previous works (Benzaazoua et al., 2002, 2004a, 2004b), the general use portland cement (Type $I=G U$ ) can be used with non-reactive tailings/water for CMB preparation. In contrast, only sulfate-resistant binders (Type II = MS, and Type V $=$ HS) or blended binders (e.g. $B b=\mathrm{GU} / \mathrm{GGBS}$ or $B b=\mathrm{GU} / \mathrm{FaF}$ ) must be used with reactive tailings/water for $\mathrm{CMB}$ preparation in order to improve the long-term strength development. It was also found that GBFS blended binder (or slag cement) up to $90 \%$ of GBFS is relatively suitable for use in all classes of sulfate conditions depending on the tailings grain size distribution (Belem et al., 2000; Belem and Benzaazoua, 2008; Benzaazoua et al., 2002, 2004a, 2004b, 2008, 2010).

The hydraulic activity index $H_{a}$ (Equation (9)) can be used in order to discriminate any type of binder/blended binder with regard to a relative reference binder/blended binder. Based on existing results, we suggest a reference blended binder $B b_{\text {ref }}=20 \mathrm{GU} / 80 \mathrm{GBFS}$ (this notation follows CSA A3001 standard) which is a blend of $80 \mathrm{wt} \%$ GBFS and $20 \mathrm{wt} \% \mathrm{GU}$ (can be termed 'slag cement'). However, other types of binder/blended binder could be selected as reference, for example $80 \mathrm{GBFS} / 20 \mathrm{HS}, 60 \mathrm{GBFS} / 40 \mathrm{HS}$, $70 \mathrm{GBFS} / 30 \mathrm{GU}$, etc. For the reference blended binder $B b_{\text {ref, }}$ the hydraulic activity index given by Equation (9b) becomes:

$$
H_{a}\left(B b_{\text {ref }}\right)=\left(\frac{H m_{B b_{-} \text {ref }}}{H m_{G U}}\right)^{2}\left(\frac{R_{f}(G U)}{R_{f}\left(B b_{\text {ref }}\right)}\right)^{0.5} \quad 0 \leq H_{a} \leq 1
$$

Table 3 presents the mean calculated main parameters values of the relative reference blended binder $B b_{\text {ref }}(=$ 80GGBS/20GU) compared to other binders (data are taken from Tables 1 and 2). 
Table 3 Main parameters of the reference $\left(B b_{\text {ref }}=80 G G B S / 20 G U\right)$ and other blended binders

\begin{tabular}{lllllllllll}
\hline Parameter & $\boldsymbol{B} \boldsymbol{b}_{\text {ref }}$ & $\mathbf{I}=\mathbf{G U}$ & $\mathbf{I I}=\mathbf{M S}$ & $\mathbf{I I I}=\mathbf{H E}$ & $\mathbf{I V}=\mathbf{L H}$ & $\mathbf{V}=\mathbf{H S}$ & $\mathbf{F a F}$ & $\mathbf{F a C}$ & GGBS & SF \\
\hline $\mathrm{R}_{\mathrm{f}}(\mathrm{Bb})$ & 16.415 & 17.435 & 16.784 & 17.262 & 21.420 & 17.848 & 24.990 & 10.836 & 16.170 & 7.050 \\
$\mathrm{Hm}_{\mathrm{Bb}}$ & 1.025 & 2.242 & 2.177 & 2.240 & 1.965 & 2.127 & 0.058 & 0.356 & 0.839 & 0.018 \\
$\mathrm{HA}_{\mathrm{I}}(\mathrm{Bb})$ & 0.215 & 1.000 & 0.961 & 1.003 & 0.693 & 0.889 & 0.0006 & 0.021 & 0.145 & 0.0001 \\
\hline
\end{tabular}
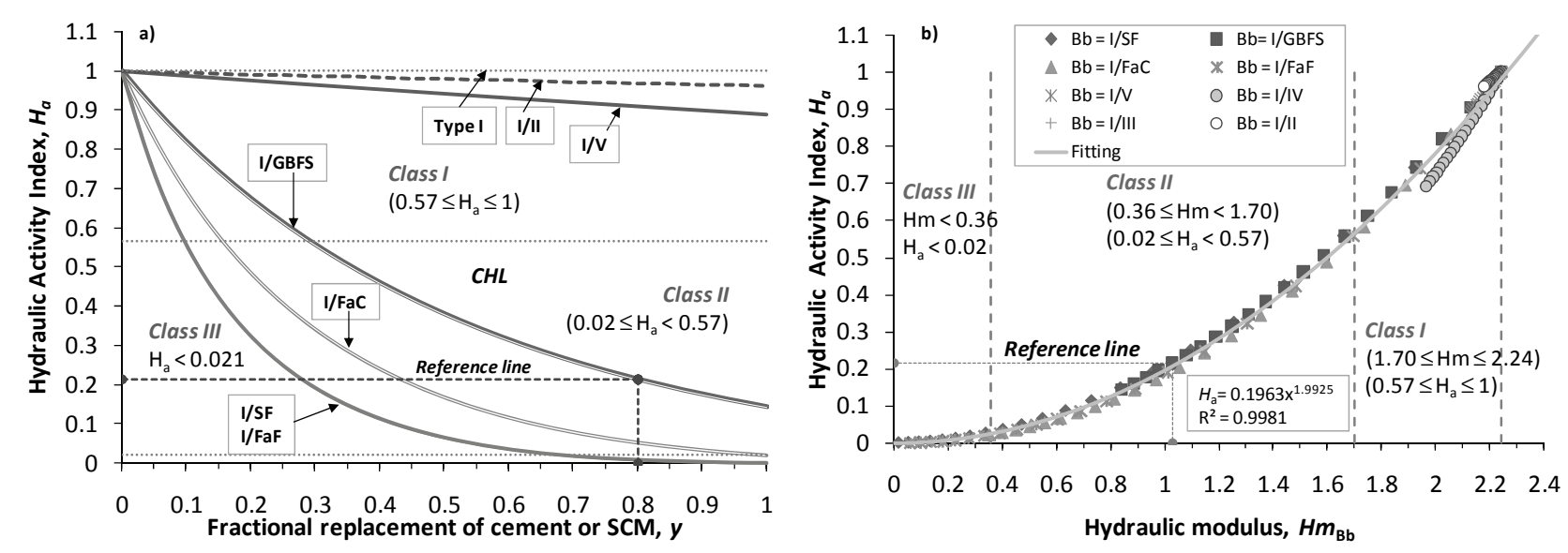

Figure 3 Theoretical curves of $H A_{I}$ showing the different classes of binder and the reference blended binder: a) as a function of fractional replacement $y$ for GU cement; b) as a function of hydraulic modulus $\mathrm{Hm}$

\subsubsection{Concept of corresponding hydraulicity}

Figure 3a presents the theoretical evolution curves of $H_{\mathrm{a}}$ for typical binders/blended binders that can be used in mine backfilling. From this figure, it can be seen that most binders fall into the category of class I (early age performance purpose) and class II (long term performance purpose) blended binders. $H_{\mathrm{a}}$ varies in the range $0.57-1$ for class I, $0.02-0.57$ for class II, and $<0.021$ for class III blinded binders. The purpose of the proposed model (Equation (9)) is also to make it possible for controlling the self-cementing ability (SCA) of binders by adjusting their hydraulic modulus in conjunction with their known physicochemical properties. If the assumptions made in relation to the formulation of Equation (9) is accurate, then by plotting the hydraulic activity index $H_{\mathrm{a}}(\mathrm{Bb})$ as a function of the hydraulic modulus $H m_{\mathrm{Bb}}$, it should be observed that all the calculated data points for all types of blended binder should be perfectly correlated $(r=1)$. This procedure is called 'concept of corresponding hydraulicity' which is comparable to the 'corresponding state' theorem for the imperfect gas in thermodynamics. To verify this, $H m_{\mathrm{B} / \mathrm{Bb}}$ and $H_{\mathrm{a}}(B / B b)$ were calculated for nine binders (Types I, II, III, IV, and V cements, FaF, FaC, GBFS, and SF) and eight binary $B b(B b=\mathrm{I} / \mathrm{II}$, $\mathrm{I} / \mathrm{III}, \mathrm{I} / \mathrm{IV}, \mathrm{I} / \mathrm{V}, \mathrm{I} / \mathrm{FaF}, \mathrm{I} / \mathrm{FaC}, \mathrm{I} / \mathrm{GBFS}$, and I/SF). For each binary $B b$, proportion of portland cement Type I (GU) replacement ranged from 0-100. Figure 3b shows the evolution of $H_{\mathrm{a}}$ with $H m$ for the 9 binders and 8 binary blended binders. The data used (chemical composition and physical properties) are taken from Tables 1 and 2 (mean values).

From Figure $3 b$, it can be seen that all the data points (for $B$ and $B b)$ are highly correlated $(r=0.999 \approx 1)$. This means that $H_{\mathrm{a}}$ can be predicted well for any binder or blended binder by knowing its hydraulic modulus $\mathrm{Hm}$ and using the following power law relation:

$$
H_{a}(B, B b) \cong 0.1963\left(H m_{B, B b}\right)^{1.9925} \quad \text { with } r=0.999
$$

This high correlation suggests that the concept of corresponding hydraulicity is valid and that the way the parameter $H_{\mathrm{a}}$ is formulated is scientific. Therefore, the $H_{\mathrm{a}}$ can be used with high level of confidence for preliminary formulation of blended binders in cemented mine backfill mix design purpose. 


\subsubsection{Matching the reference blended binder hydraulicity}

As a reference blended binder is defined $\left(B b_{\text {ref }}\right)$, any blended binder $B b$ can be matched to this reference by making some adjustments or optimisation (either on the amount of oxides or the physical properties such as fineness $S_{\mathrm{m}}$ ) in order to get the same hydraulic activity index $H_{\mathrm{a}}(B b)$. After physicochemical adjustments, some trial batches must be prepared necessarily for performance verification. If the adjustment relates to binary blended binders, the simplest way to determine the fractional proportion of portland cement replacement is the use of Figure $3 \mathrm{a}$ (selected types of blended binder are: I/SF, I/FaF, I/FaC, I/GGBS, I/V and $\mathrm{I} / \mathrm{II}$ ). In this figure, each horizontal line refers to a 'Corresponding Hydraulicity Line' (CHL). It can be seen that the curves of blended portland cements stand above all the other curves; that is to say that every intercept between CHL and $H_{\mathrm{a}}(B b)$ curves for different types of blended binder will exhibit corresponding hydraulicity. The fractional amount $y$ to be used can then be determined graphically. For example, by using the CHL passing through the $H_{\mathrm{a}}\left(B b_{\text {ref }}\right)$ curves at point $(0.8,0.215)$ it can be derived that the blended binders $71 \mathrm{I} / 29 \mathrm{FaF}$ and $53 \mathrm{I} / 47 \mathrm{FaC}$ have the same $H_{\mathrm{a}}(=0.215)$ than the reference blended binder $\left(B b_{\text {ref }}=\right.$ 20I/80GGBS). Therefore, these two formulations should produce the same hydraulicity of the binders than the reference one. Note that it is nearly impossible to make a direct link between $H_{\mathrm{a}}$ and the resultant anticipated mechanical performance. This parameter is used only in the formulation or selection of blended binders suitable for use in $\mathrm{CMB}$ materials.

The adjustment can also be made theoretically. For any given blended binder $B b_{\mathrm{x}}\left(=y_{0} \mathrm{GU} / y_{1} \mathrm{AA} / y_{2} \mathrm{BB} / \ldots\right)$ to match the reference blended binder $B b_{\text {ref, }}$, the following equality must be satisfied:

$$
H_{a}\left(B b_{\mathrm{x}}\right)=H_{a}\left(B b_{\text {ref }}\right)=0.215
$$

From Equation (12), the hydration modulus of the blended binder $B b_{\mathrm{x}}$ can be calculated as follows:

$$
H m_{B b_{-} \mathrm{x}}=\frac{\% C_{B b_{-} \mathrm{x}}}{\% S_{B b_{-} \mathrm{x}}+\% A_{B b_{-} \mathrm{x}}+\% F_{B b_{-} \mathrm{x}}}=H m_{G U} \cdot \sqrt{0.215\left(R_{f}\left(B b_{x}\right) / R_{f}(G U)\right)^{0.5}}
$$

From Equation (13) it can be seen that matching the hydraulicity of the reference blended binder $B b_{\text {ref }}$ may need some adjustments to binder fineness (or particle average diameter) or amount of oxides. For optimising the lime content $\left(\% C_{\mathrm{Bb}_{-} \mathrm{x}}\right)$, the amount of oxides $y_{\mathrm{i}}$ can be manipulated in the following relation:

$$
\% C_{B b_{-} \mathrm{x}}=\left(\% S_{B b_{-} \mathrm{x}}+\% A_{B b_{-} \mathrm{x}}+\% F_{B b_{-} \mathrm{x}}\right) \cdot H m_{G U} \cdot \sqrt{0.215\left(R_{f}\left(B b_{x}\right) / R_{f}(G U)\right)^{0.5}}
$$

Where:

$$
\begin{array}{lll}
\% C_{\mathrm{Bb} \_\mathrm{x}} & = & y_{0}(\% \mathrm{CaO})_{0}+y_{1}(\% \mathrm{CaO})_{1}+y_{2}(\% \mathrm{CaO})_{2}+\ldots . \\
\% S_{\mathrm{Bb} \_\mathrm{x}} & = & y_{0}\left(\% \mathrm{SiO}_{2}\right)_{0}+y_{1}\left(\% \mathrm{SiO}_{2}\right)_{1}+y_{2}\left(\% \mathrm{SiO}_{2}\right)_{2}+\ldots \\
\% A_{\mathrm{Bb} \_\mathrm{x}} & = & y_{0}\left(\% \mathrm{Al}_{2} \mathrm{O}_{3}\right)_{0}+y_{1}\left(\% \mathrm{Al}_{2} \mathrm{O}_{3}\right)_{1}+y_{2}\left(\% \mathrm{Al}_{2} \mathrm{O}_{3}\right)_{2}+\ldots . \\
\% \mathrm{~F}_{\mathrm{Bb} \_\mathrm{x}}= & y_{0}\left(\% \mathrm{Fe}_{2} \mathrm{O}_{3}\right)_{0}+y_{1}\left(\% \mathrm{Fe}_{2} \mathrm{O}_{3}\right)_{1}+y_{2}\left(\% \mathrm{Fe}_{2} \mathrm{O}_{3}\right)_{2}+\ldots .
\end{array}
$$

$H m_{\mathrm{GU}}=$ hydraulic modulus of GU cement and is calculated using Equation $(5 \mathrm{a}) ; R_{f}\left(B b_{\mathrm{x}}\right)$ and $R_{f}(G U)=$ reactivity factor of the binder $B b_{\mathrm{x}}$ and GU cement, respectively are calculated using Equation (8). For optimising the silica $\% S_{\mathrm{Bb}_{-} \mathrm{x}}$, alumina $\% A_{\mathrm{Bb}_{-} \mathrm{x}}$ and ferrite $\% F_{\mathrm{Bb}_{-} \mathrm{x}}$ contents, their amount $y_{\mathrm{i}}$ can also be derived using the following relation:

$$
\% S_{B b_{-} \mathrm{x}}+\% A_{B b_{-} \mathrm{x}}+\% F_{B b_{-} \mathrm{x}}=\frac{\% C_{B b_{-} \mathrm{x}}}{H m_{G U} \cdot \sqrt{0.215\left(R_{f}\left(B b_{x}\right) / R_{f}(G U)\right)^{0.5}}}
$$

\subsubsection{Long-term relative strength development index}

As previously mentioned, it was found that the correlation between hydraulicity and the strength of blended binder is rarely good, e.g. Wang et al., 1994; Pal et al., 2003. Therefore, there is a need of another parameter that can account for this limitation. From numerous existing data, it was found that GBFS greatly influences 
the long-term strength development (or hardening) of CMB materials. Based on this knowledge, the authors propose the 'Long-term Relative Strength Development Index' $\left(S D I_{r}\right)$ of class II blended binders $(0.36 \leq$ $H m_{\mathrm{Bb}}<1.70$ and $\left.0.02 \leq H_{\mathrm{a}}<0.57\right)$, which is defined as follows:

$$
\left.S D I_{r}(B b)\right|_{\text {Class II }}=\frac{\left(h m_{b-G B F S}\right)_{B b} \cdot H m_{B b}+H_{a}(B b)}{\left(h m_{b-G B F S}\right)_{B b_{-} \text {ref }} \cdot H m_{B b \_ \text {ref }}+H_{a}\left(B b_{\text {ref }}\right)} \leq 1.0
$$

Where:

$\left(h m_{\mathrm{b}-\mathrm{GBFS}}\right)_{\mathrm{Bb} / \mathrm{Bb} \_ \text {ref }}, H m_{\mathrm{Bb} \_ \text {ref }}$ and $H m_{\mathrm{Bb}}=$ fractional hydraulic modulus of GBFS in the blend

(Equation (5b)) and the hydraulic modulus of reference or any blended binder (Equation (5a)), respectively.

$H_{\mathrm{a}}(\mathrm{Bb})$ and $H_{\mathrm{a}}\left(B b_{\text {ref }}\right)=$ hydraulic activity index of the blended binder (Equation (9b)) and the reference blended binder (Equation 10), respectively.

Figure 4 shows the theoretical evolution curves of $S D I_{r}$ as a function of hydraulic modulus (Figure $4 a$ ) and hydraulic activity index $H_{\mathrm{a}}$ (Figure 4b). This figure shows clearly that the curve of other binders behave very differently from that of GU/GBFS binders as it is the only binder that contains GBFS (see Equation (16)). This trend suggests that even for a same given hydraulic modulus $H m_{\mathrm{Bb}}$ or $H_{\mathrm{a}}$ the other binders will potentially develop different level of long-term strength than that from GBFS blended binders. For a blended binder $B b$ develops a strength close to that of the reference blended binder $B b_{\text {ref, }} S D I_{r}(B b)$ must be equal to $S D I_{r}\left(B b_{\text {ref }}\right)=1$. However, the range of variation around $1(<1)$ is unknown at this stage since it will depend on many factors such as curing condition, binder content and mixing water geochemistry.
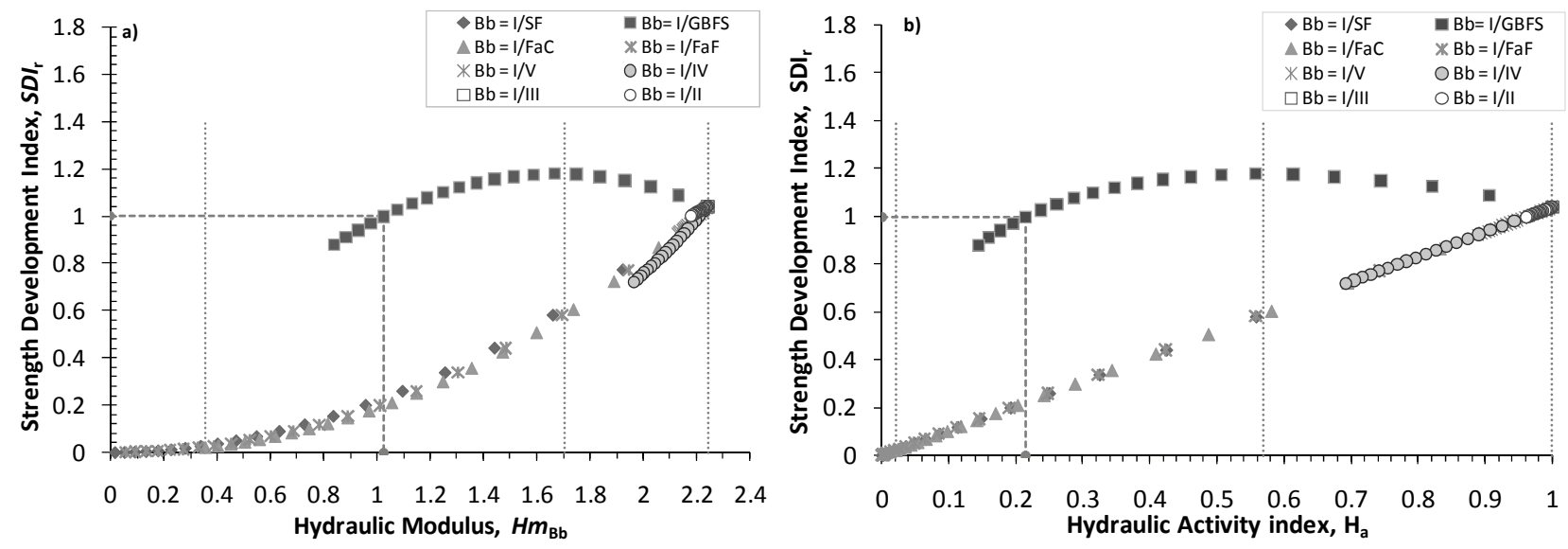

Figure 4 Theoretical evolution curves of $S D I_{r}$ as a function of: a) hydraulic modulus $\mathrm{Hm}$; b) hydraulic activity index $H_{\mathrm{a}}$

In order to facilitate the calculation of various proposed parameters $\left(H m_{\mathrm{Bb}}, h m_{\mathrm{b}-\mathrm{GBFS}}, H A_{\mathrm{I}}\right.$ and $\left.S D I_{\mathrm{r}}\right)$ for the case of binary mixtures, different fitting models are proposed and are given as follows:

$$
H m_{B b} \approx \frac{a+b \cdot y_{B}}{1+c \cdot y_{B}+d \cdot y_{B}^{2}}
$$

Where:

$y_{\mathrm{B}}$

$a, b, c$ and $d \quad=\quad$ fitting constants whose values are listed below for different types of binder $(r=1)$. 
Table 4 Chemical composition and physical properties of cement and SCM used

\begin{tabular}{ccccccccc}
\hline & II & III & IV & V & FaF & FaC & GBFS & SF \\
\hline a & 2.24211 & 2.24210 & 2.24208 & 2.24214 & 2.24211 & 2.24211 & 2.242107 & 2.24211 \\
b & 0.40039 & 0.44247 & 0.22977 & 0.36250 & -2.06667 & -1.50529 & -0.87371 & -2.18597 \\
c & 0.20821 & 0.19815 & 0.23997 & 0.21601 & 2.01757 & 1.07020 & 0.63158 & 2.18598 \\
d & 0.00535 & 0.00017 & 0.01768 & 0.00867 & $-5.40 \mathrm{E}-05$ & $-7.78 \mathrm{E}-05$ & $-2.48 \mathrm{E}-05$ & $-4.12 \mathrm{E}-05$ \\
\hline
\end{tabular}

The fractional hydraulic modulus of GBFS in a binary blend $h m_{\mathrm{b}-\mathrm{GBFS}}$ can be calculated using the following fitting model:

$$
h m_{b-G B F S} \cong 1.3251\left[1.0022-\exp \left(-0.9907 \cdot y_{B}\right)\right] \quad \text { with } \quad r=0.99998
$$

After calculating $H m_{\mathrm{Bb}}$ from Equation (17), the hydraulic activity index $H A_{\mathrm{I}}$ can then be calculated from Equation (11) $(r=0.999)$. The long-term relative strength development index $S D I_{\mathrm{r}}$ for the blends not containing GBFS can be calculated using the following fitting model:

$$
S D I_{r}(B b) \cong 1.0405 \cdot H A_{I} \quad \text { with } \quad r=1
$$

And for the blends containing GBFS, the following fitting model can be utilised:

$$
S D I_{r}(\mathrm{GU} / \mathrm{GBFS}) \cong 2.5956 \cdot(0.4049)^{H A_{I}} \cdot\left(H A_{I}\right)^{0.4938} \quad \text { with } \quad r=0.999
$$

\section{Sample application}

\subsection{Characteristics of binder used}

Table 4 contains the chemical composition of the different binders and industrial by-products used for blended binder formulation. This table also contains their physical properties, such as BET specific surface area $S_{\mathrm{m}}$, relative density $\rho_{\mathrm{s}}$ of grain and median particle diameter $d_{\mathrm{av}}\left(=D_{50}\right)$.

Table 5 Chemical composition and physical properties of cement and SCM used

\begin{tabular}{lllllllll}
\hline Type of Cement & $\begin{array}{l}\mathbf{S i O}_{2} \\
(\mathbf{w t} \%)\end{array}$ & $\begin{array}{l}\mathrm{Al}_{2} \mathbf{O}_{3} \\
(\mathbf{w t} \%)\end{array}$ & $\begin{array}{l}\mathbf{F e}_{2} \mathbf{O}_{3} \\
(\mathbf{w t} \%)\end{array}$ & $\begin{array}{l}\mathbf{C a O} \\
(\mathbf{w t} \%)\end{array}$ & $\begin{array}{l}\mathbf{M g O} \\
(\mathbf{w t} \%)\end{array}$ & $\begin{array}{l}\mathbf{B E T} \boldsymbol{S}_{\mathbf{m}} \\
\left(\mathbf{c m}^{2} / \mathbf{g}\right)\end{array}$ & $\begin{array}{l}\boldsymbol{\rho}_{\mathbf{s}} \\
\left(\mathbf{g} / \mathbf{c m}^{\mathbf{3}}\right)\end{array}$ & $\begin{array}{l}\boldsymbol{d}_{\mathbf{a v}} \\
(\mathbf{c m})\end{array}$ \\
\hline GU & 21.2 & 4.69 & 2.79 & 63 & 2.26 & 11,000 & 3.14 & 0.001411 \\
GGBS & 37 & 9.48 & 0.6 & 36.8 & 12.8 & 27,500 & 2.90 & 0.000725 \\
Anhydrite & 0.5 & 0.4 & 0.13 & 42.7 & 0.07 & 13,100 & 2.95 & 0.00105 \\
CKD & 8.49 & 4.43 & 1.32 & 33.0 & 1.01 & 29,300 & 2.79 & 0.000816 \\
CA1SiFrit & 35.00 & 14.60 & 2.50 & 21.60 & 0.64 & 17,700 & 2.71 & 0.001344 \\
Copper Smelter Slag, CS & 22.90 & 4.78 & 54.10 & 1.68 & 1.63 & 13,900 & 4.06 & 0.000615 \\
Glass & 71.50 & 1.74 & 0.40 & 10.90 & 0.91 & 9,500 & 2.49 & 0.002499 \\
\hline
\end{tabular}

\subsection{Types of blended binder, CMB mixtures and UCS results}

Table 5 summarises the types of blended binder formulation, their names, the calculated reactivity factor $R_{\mathrm{f}}(B b)$, the hydration modulus $H m_{\mathrm{Bb}}$, the hydraulic activity index $H A_{\mathrm{I}}(B b)$, and the long-term relative strength development index $S D I_{\mathrm{r}}(B b)$. This table contains also the results of 56 day and 119 day curing times unconfined compressive strength (UCS) of CMB prepared with $4.5 \mathrm{wt} \%$ binder. First of all, recall that $H A_{\mathrm{I}}(\mathrm{Bb})$ values are calculated using BET specific surface area $S_{\mathrm{m}}$ which is at least three times higher than Blaine specific surface area $S_{\mathrm{m}}$. Therefore, BET $S_{\mathrm{m}}$ were first divided by 3 to get an equivalent Blaine $S_{\mathrm{m}}$. 
Except for the control binder (GU cement), all the blended binders tested can be classified as class II blended binders $\left(0.02 \leq H A_{\mathrm{I}} \leq 0.57\right)$. In addition, it can be seen a clear proportionality between $S D I_{\mathrm{r}}$ (except for GU cement) and UCS values.

Table 5 also shows that the highest UCS after 119 days of curing time (UCS $=1,853 \mathrm{kPa}$ ) was obtained with the Slag cement (designated as the reference binder in this paper), as expected. Other binders with which UCS > $1 \mathrm{MPa}$ was obtained are Glass3, Glass6, CS3, CS6 and CalSiFrit3. These results also confirmed that the long-term strength development is directly proportional to the amount of GBFS present in the blend. The best UCS values were obtained with either 25 or $50 \%$ of GBFS added.

Table 6 Calculated hydration parameters and the UCS results

\begin{tabular}{|c|c|c|c|c|c|c|c|}
\hline \multirow{2}{*}{$\begin{array}{l}\text { Binder Blended Binder Types* } \\
\text { (Binder Content }=4.5 \mathrm{wt} \% \text { ) }\end{array}$} & \multirow[t]{2}{*}{ Name } & \multicolumn{4}{|c|}{ Model Parameters } & \multicolumn{2}{|c|}{ UCS (kPa) } \\
\hline & & $R_{f}(B b)$ & $H m_{\mathrm{Bb}}$ & $H_{\mathrm{a}}(B b)$ & $S D I_{\mathrm{r}}(B b)$ & 56-d & 119-d \\
\hline GU (Control binder) & $\mathrm{GU}$ & 16.245 & 2.197 & 1.000 & 1.187 & 311 & 391 \\
\hline 20GU/80GGBS (Reference binder) & Slag cement & 17.905 & 0.969 & 0.185 & 1.000 & 1,757 & 1,853 \\
\hline 33G/43GU/19A/5CKD & Glass 1 & 21.741 & 0.866 & 0.156 & 0.185 & 302 & 324 \\
\hline $25 \mathrm{G} / 32 \mathrm{GU} / 13 \mathrm{~A} / 25 \mathrm{GGBS} / 5 \mathrm{CKD}$ & Glass2 & 23.450 & 0.842 & 0.146 & 0.354 & 628 & 712 \\
\hline 16G/20GU/9A/50GGBS/5CKD & Glass3 & 20.501 & 0.823 & 0.133 & 0.617 & 1,091 & 1,243 \\
\hline 48G/33GU/14A/5CKD & Glass4 & 19.176 & 0.608 & 0.149 & 0.177 & 197 & 249 \\
\hline $35 \mathrm{G} / 25 \mathrm{GU} / 10 \mathrm{~A} / 25 \mathrm{GGBS} / 5 \mathrm{CKD}$ & Glass5 & 18.457 & 0.670 & 33 & 0.431 & 644 & 776 \\
\hline $23 \mathrm{G} / 15 \mathrm{GU} / 7 \mathrm{~A} / 50 \mathrm{GGBS} / 5 \mathrm{CKD}$ & Glass6 & 18.097 & 0.704 & 0.130 & 0.623 & 1,003 & 1,111 \\
\hline $27 \mathrm{CS} / 48 \mathrm{GU} / 20 \mathrm{~A} / 5 \mathrm{CKD}$ & CS1 & 17.958 & 0.885 & 0.085 & 0.101 & 212 & 282 \\
\hline $21 \mathrm{CS} / 34 \mathrm{GU} / 15 / 25 \mathrm{GGBS} / 5 \mathrm{CKD}$ & $\mathrm{CS} 2$ & 17.606 & 0.828 & 0.091 & 0.317 & 496 & 577 \\
\hline $14 \mathrm{CS} / 22 \mathrm{GU} / 9 \mathrm{~A} / 50 \mathrm{GGBS} / 5 \mathrm{CKD}$ & $\mathrm{CS}$ & 17 & 0. & 0 & 0.532 & 1,007 & 1,045 \\
\hline 37CS/41GU/17A/5CKD & CS4 & 22.606 & 0.658 & 0.132 & 0.156 & 191 & 225 \\
\hline $28 \mathrm{CS} / 29 \mathrm{GU} / 13 \mathrm{~A} / 25 \mathrm{GGBS} / 5 \mathrm{CKD}$ & CS5 & 21.332 & 0.677 & 0.128 & 0.417 & 455 & 518 \\
\hline $18 \mathrm{CS} / 19 \mathrm{GU} / 8 \mathrm{~A} / 50 \mathrm{GGBS} / 5 \mathrm{CKD}$ & CS6 & 20.699 & 0.728 & 0.124 & 0.617 & 1,034 & 1,037 \\
\hline 48CSF/33GU/14A/5CKD & CalSiFrit1 & 21.898 & 0.932 & 0.066 & 0.078 & 366 & 405 \\
\hline $35 \mathrm{CSF} / 25 \mathrm{GU} / 10 \mathrm{~A} / 25 \mathrm{GGBS} / 5 \mathrm{CKD}$ & CalSiFrit2 & 21.172 & 0.919 & 0.081 & 0.290 & 688 & 758 \\
\hline 23CSF/156GU/7A/50GGBS/5CKD & CalSiFrit3 & 20.785 & 0.850 & 0.091 & 0.487 & 969 & 1,070 \\
\hline
\end{tabular}

* It should be noted that some amount of 'The amount of $\mathrm{CaSO}_{4}$ ' was not taken into account in the calculation of hydration modulus Hm.

$\mathrm{GU}=$ general use portland cement (Type I).

$\mathrm{A}=$ anhydrite $\left(\mathrm{CaSO}_{4}\right)$.

$\mathrm{G}=$ glassy material.

$\mathrm{CKD}=$ cement kiln dust.

$\mathrm{CS}=$ copper smelter slag.

GGBS $=$ market ground granulated blast furnace slag.

$\mathrm{CSF}=$ CalsiFrit material.

\subsection{Correlation between $S D I_{\mathrm{r}}(B b)$ and UCS}

For the purpose of validating Equation (16), would require the parameter $S D I_{\mathrm{r}}(B b)$ is correlated with long term UCS values (curing time $\geq 56$ days). 

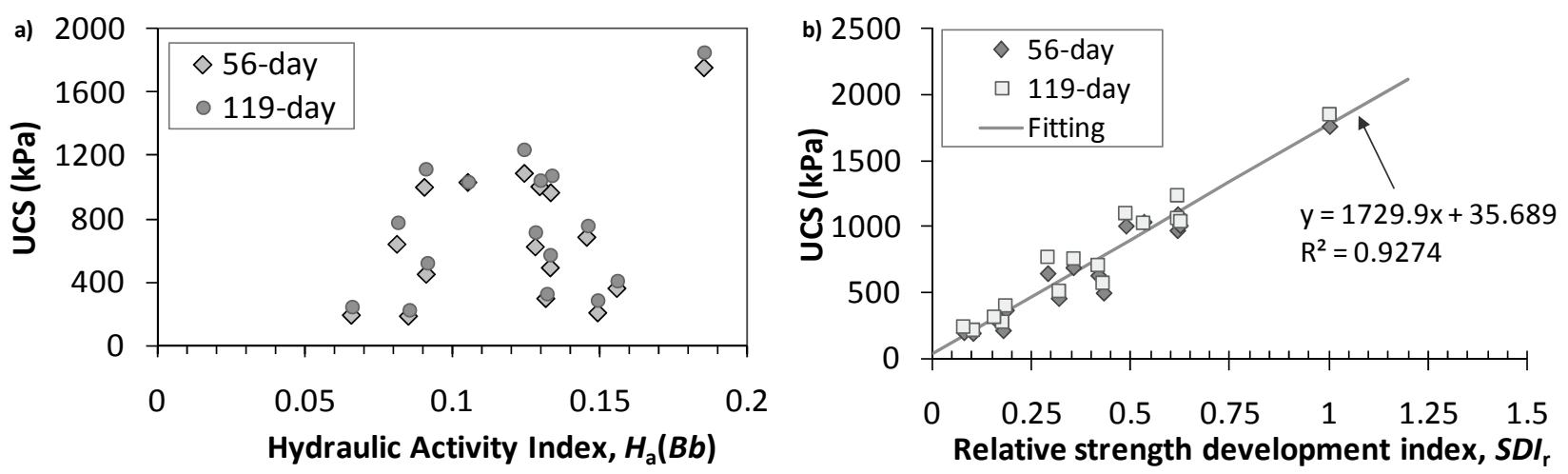

Figure 6 Correlation between UCS and: a) $H_{\mathrm{a}}(B b)$; b) $S D I_{\mathrm{r}}(B b)$

Figure 6a first presents the relationship between $H A_{\mathrm{I}}(B b)$ and long term (56 and 119 day curing times) UCS for all blended binders tested. It can be seen that there is no clear correlation between these two parameters. This result confirms what numerous investigators have found previously (Wang et al., 1994, Pal et al., 2003). The main reason is that the parameter $H_{\mathrm{a}}(B b)$ is not able to adequately quantify the increase in the proportion of GBFS in the blend only through hydraulic modulus $H m_{\mathrm{Bb}}$. It is therefore a qualitative parameter rather than a quantitative one. Figure $6 \mathrm{~b}$ shows the relationship between long term UCS and the long-term strength potential $S D I_{\mathrm{r}}$. It can be seen a good correlation $(r=0.96)$ between these two parameter which is very promising for the future.

\section{Conclusion}

This paper presents a model with two physicochemical parameters, namely the hydraulic activity (or hydraulicity) index $H_{\mathrm{a}}(B b)$ and the long-term relative strength development index $S D I_{\mathrm{r}}(B b)$ of blended binders for use in cemented mine backfill (CMB). These parameters were formulated based on the proposed hydraulic modulus $H m_{\mathrm{Bb}}$ and reactivity factor $R_{f}(B b) . H m_{\mathrm{Bb}}$ was defined based on the chemical composition (main oxides) of each single binder in the blend, whereas $R_{f}(B b)$ was defined based on the binder physical properties. $H_{\mathrm{a}}(\mathrm{Bb})$ can be used to discriminate three different classes of blended binder: Class I (conventional cements) for early age performance, Class II (SCM blended binders) for long-term performance, and Class III (nearly non hydraulic binders). The advantage of this model is to help better formulation of chemical composition and proportions required for blended binders for use in CMB mix design. A relative 'reference' binary blended binder $\left(B b_{\text {ref }}=20 \mathrm{GU} / 80 \mathrm{GBFS}\right)$ was proposed as a way of comparing the hydraulicity of any blended binder. From the proposed model and based on $B b_{\text {ref, }}$ it is possible to formulate a given blended binder in order to match the hydraulicity of $B b_{\text {ref }}\left[=H_{\mathrm{a}}\left(B b_{\text {ref }}\right)\right]$. A sample application using 16 types of blended binder shows a good correlation between $S D I_{\mathrm{r}}(B b)$ and the long-term (curing time $\geq 56$ days) UCS data, which is very promising. Therefore, it is clear that the proposed model $\left[H_{\mathrm{a}}(B b)\right.$ and $\left.S D I_{\mathrm{r}}(B b)\right]$ could be used to help better formulation of blended binders for cemented mine backfill in order to reduce the number of trial batches necessary for optimising mix recipes.

\section{Acknowledgements}

This research project was financially supported by the IRSST and parts of Fondation-UQAT funds. The authors gratefully acknowledge their support.

\section{References}

American Concrete Institute Committee 211 (ACI) (1998) Standard Practice for Selecting Proportions for Structural Lightweight Concrete, ACI 211.2-98, American Concrete Institute, Farmington Hills, Michigan, 1998, 14 p.

Belem, T., Benzaazoua, M. and Bussière, B. (2000) Mechanical behaviour of cemented paste backfill, in Proceedings 53th Canadian Geotechnical Conference, 'Geotechnical Engineering at the dawn of the third millennium', 15-18 October 2000, Montreal, Vol. 1, pp. 373-380.

Belem, T. and Benzaazoua, M. (2007) Underground mine paste backfill technology: applications and design methods, Geotechnical and Geological Engineering, Vol. 26(2), pp. 147-174. 
Belem, T. and Benzaazoua, M. (2008) Predictive models for prefeasibility cemented paste backfill mix design, in Proceedings International Symposium on Post-Mining 2008, Nancy, France, February 6-8, CD.

Benzaazoua, M., Belem, T. and Bussière, B. (2002) Chemical factors that influence on the performance of mine sulphidic paste backfill, Cement and Concrete Research, Vol. 32(7), pp. 1133-1144.

Benzaazoua, M., Fall, M. and Belem, T. (2004a) A contribution to understanding the hardening process of cemented pastefill, Minerals Engineering, Vol. 17(2), pp. 141-152.

Benzaazoua, M., Marion, P., Picquet, I. and Bussière, B. (2004b) The use of pastefill as a solidification and stabilization process for the control of acid mine drainage, Minerals Engineering, Vol. 17(2), pp. 233-243.

Benzaazoua, M., Bussière, B., Demers, I., Aubertin, M., Fried, E. and Blier, A. (2008) Integrated mine tailings management by combining environmental desulphurization and cemented paste backfill: Application to mine Doyon, Quebec, Canada, Minerals Engineering, Vol. 21(4), pp. 330-340.

Benzaazoua, M., Peyronnard, O., Belem, T., Fried, E., Stephant, D. and Dublet, G. (2010) Key issues related to behavior of binders in cemented paste backfilling, in Proceedings Thirteenth International Seminar on Paste and Thickened Tailings (Paste2010), R. Jewell and A.B. Fourie (eds), 3-6 May 2010, Toronto, Canada, Australian Centre for Geomechanics, Perth, pp. 345-364.

Bouzoubaâ, N. and Fournier, B. (2005) Current situation with the production and use of supplementary cementitious materials (SCMs) in concrete construction in Canada, Canadian Journal of Civil Engineering, Vol. 32, pp. 129-143.

Grice, T. (1998) Underground mining with backfill, Proceedings of the 2nd Annual Summit on Mine Tailings Disposal Systems, 1998, Brisbane, 14 p.

Kamon, M. and Nontananandh, S. (1991) Combining industrial wastes with lime for soil stabilization, Journal of Geotechnical Engineering, Vol. 117(1), pp. 1-17.

Mindess, S. and Young J.F. (1981) Concrete, Englewood Cliffs, N.J.: Prentice-Hall, Inc.

Pal, S.C., Mukherjee, A. and Pathak, S.R. (2003) Investigation of hydraulic activity of ground granulated blast furnace slag in concrete, Cement and Concrete Research, Vol. 33, pp. 1481-1486.

Wang, S.D., Scrivener, K.L. and Pratt, P.L. (1994) Factors affecting the strength of alkali-activated slag, Cement and Concrete Research, Vol. 24(6), pp. 1033-1043. 
